\title{
"Someone Who Looks Like Me". Search for Origin and Adoptive Kinship in Italy
}

\author{
Rossana DiSilvio \\ University of Milano-Bicocca \\ E-mail: r.disilvio@campus.unimib.it
}

\author{
Doi:10.5901/mjss.2013.v4n14p755
}

\begin{abstract}
The origins' issue seems to be at the core of the identity construction of adopted children. This viewpoint is sustained by many social studies and has been recently highlighted by the ethnographic investigation carried out with the adoptees' associations active in the public arena of the so-called 'receiving' Western countries. The disciplines involved in the establishment and management of the adoptive kinning, mainly the 'psy' sciences, seem to be oriented to use preventing-repairing techniques, which alert especially the adoptive parents (but also the school) to the destabilizing effects of this kind of 'fracture', so emotionally difficult to understand and justify since it founds the identity and belonging of a person. By using an ethnoanthropological glance, my contribution aims at introducing a reflection on how the 'claim' to know the origins is an intrinsic aspect of the Western adoptive device, through a discussion - in a cultural sense - on the dimensions of the incompleteness of belonging and on their construction starting from the nature-culture dichotomy, with particular reference to the domestic domain and kinship ties. In this framework, the identity re-composition pursued by the adoptees seems to spring from a 'poietic' tension pushed by an aspiration to completeness, longed-for but never fully achieved. However, this condition of identity fragmentation also seems to guide the adoptees to creatively produce themselves as subjects having multiple belongings but being internally coherent, thus giving new shapes to the cultural meaning of 'being kin' and of 'being-in-thekinship'.
\end{abstract}

Keywords: adoptive kinship; origin; identity; belonging; nature-culture; in-/completeness; poiesis;

\section{Introduction}

The small elementary school gymnasium has been arranged with several rows of blue chairs facing the entrance door, where an electric piano and a table were placed. When Kim Soo Bok picks up the microphone and announces, with a clear inflection of Northern Italy, the start of the "meeting", almost all participants have already taken a seat. Most of them have pinned on the chest the cards with their original Korean names, in few cases in association with the Italian name. The audience seems very happy to be here. There are mainly adults, many of whom with their children and/or partner and some with the adoptive parents, and we may hear inflections from different regions of Italy. Kim Soo Bok welcomes participants and introduces with a few words the "opening ceremony" of this "rather special event, being the first meeting that we managed to organize as Italian-Korean adoptees". Before starting the program of the day, the ceremony includes some official greetings and thanks. The first are addressed to the Consul of the Republic of South Korea, who, by standing up and with the traditional curtsey, receives warm applauses from those present. "The Consulate's contribution to this event has been remarkable", says Kim Soo Bok, and then, on behalf of the community of the "Korean-Italian adoptees" wants "to give a small gift" which, accompanied by mutual curtsies and an applause, is transferred into the hands of the Consul with the help of a lovely Korean-Italian assistant. Then it is the turn of the President of the Association of the Koreans in Italy, "whose contribution was also significant - continues Kim Soo Bok - because she helped to prepare the delicious foods that you will taste later". Then Mr. Moon is introduced, who "helped us, young Koreans, a lot; he invited us many times, he gathered us together ... He's a great reference point for us". Kim Soo Bok smiles to Mr. Moon, who is getting up to go to pick up his "gift". And finally, Kim Soo Bok warmly thanks the President of the host school and particularly the President of the adoptive agency (Italian Centre for International Adoption - CIAI), since thanks to it "we were able to organize this event, thanks to their knowledge ... I mean, our addresses ... because we've all came through the CIAI, I think ...". Lastly Kim Soo Bok remembers to the presents the opportunity to participate in several activities: cooking workshops, language courses, traditional Korean games and the performances of traditional music and singing, lunches with Korean and Italian cuisine, followed by souvenir photos of the day, a projection of the 
videos recorded by the adoptees during their travelling in Korea and, as the crucial moment of the program, the adoptees' assembly where they will discuss the twin citizenship matter, the arrangements of the "return journeys" to Korea, and especially, the establishment of the association of the Koreans adopted in Italy. (Italics is mine)

These brief ethnographic notes concern an event to which I was invited to in autumn 2011 and representing quite a unique fact within the adoptive scenario in Italy. The Korean adoptees who arrived in Italy over the 60s and 70s have decided to meet in the bright premises of a primary school of the outskirts of Milan, and to consume there the 'ceremonial' rite celebrating the birth of the first Italian association of adoptees from intercountry adoption. The uniqueness of this fact, having a purely social nature, is linked to two basic elements that are inherent to its dual nature: practical and ideological-discursive. On the one side, this event publicly discloses the Pandora's box of the presence of 'outsider' children within the family and the social and national community (in a country completely devoid of the these initiatives, although for thirty years it has been among the major 'receiving' countries for intercountry adoption), and on the other side, it brings to the fore the issue of the validation of the 'founding tool' of the Western device of adoption, that is the so called 'clean break'. A break of the origin ties made unquestionable by the law, but it is no longer clear how much this break is clean. Deftly swept under the discursive carpet of the 'best interests of the child', the question of origins bounces off more vigorous than ever at the intersection of the relations produced by the network of the 'global village' and the growing social rooting of the genomics ideology and its media discourses. If adoptive kinning is a product of the culture, then, in a world increasingly pervaded by the (scientific) accreditation of nature - understood more often as 'zoe' than as 'bios' - as the only tool of veridiction of kinship ties, the 'origin' wins, by exerting an irresistible enticement, culturally induced - in a paradoxical way - from the same society that, in the event of adoption, would 'cut' origins away, albeit in a clean way.

\section{Kinship and Oppositional Dichotomies}

Sahlins (2010) asserts that probably the antithesis between nature and culture became a question with the rise of the State and its intrusion into the 'natural' bonds of kinship. Consequently, from the fifth century b.C. the fight between kinship and polis became a recurrent topos of poetic, drama and tragedy of the classical age (e.g. Sophocles' Antigone), by spreading a new idea of the relation between nature and culture (Kahn, 1997). In the Aristotelian thought the psysis, the nature, has its own specific character of objectivity since it recognizes the objective or independent reality of the outside world. Objectivity provides for the absence of subjects and this is the distinctive quality of the Western representation of 'nature', contrasting with the vision of many other peoples living in worlds where each specific entity of the cosmos is imbued with subjectivity. However what proved to be crucial for the concept of culture in the West, especially since the Enlightenment, was to assume the sense of something false compared to the authentic character of nature (Sahlins, 2010, p.44), although, as Agamben (2005) observed, it is the culture that precedes and imposes the meaning to nature.

Over the time, kinship (and the family in particular) has kept a mystifying 'natural' representation because of the blood ties that produce it. Thus, the contemporary genetic determinism, widespread and pervasive, whose praise of naturalism is nothing more than a specific cultural construction of nature (whose symbolic qualities are nevertheless conceived as 'universal'), sacralizes the blood ties as the exclusive mark of distinction of relatives ties, and of filiation in particular. Following the idea of Aristotle (2000) that children love their parents and brothers love each other because they share "this equality that they have with those that creates these same feelings, so one says that they have the same blood, the same root, and similar things" (p.1162), many centuries later Malinowski (1930) stated that "after all, kinship is a matter of flesh and blood, the result of sexual passion and of maternal affection, of long and intimate daily life, and of a host of intimate personal interests" (p.19). The hierarchical social positioning assigned to the families (or relatives) in the West, based on the distinction between biological/natural and social/fictive kinship, shows therefore a prolonged ideological and representational tradition, established on the same opposition between nature and culture that David Schneider (1980) pointed out in his famous study on American kinship. However, over the past thirty years, many ethnoanthropological studies highlighted how the concept of relation ascribed to the kinship between identicals by Aristotle (and Malinowski) - and objectified by the sharing of the same bodily substance - has to be regarded as an incomplete concept because culturally and historically determined. Indeed, this preference for consanguinity is not an universal feature of kinship systems, nor it is found, in a general sense, among the main aspects that the 'natives' use to represent their kinship relationships. So, if it was not for the (cultural) sociobiological drift, it would be clear that being-in-the-kinship does not necessarily depend on a genealogical line of descendants or on a shared substance, but moves mainly on the plan of ethics. In fact, what seems to be universally working in the Aristotelian description of being relatives, understood 
as an unique entity shared, is based on what implies that similarity, that is the mutual feeling that feels those who are kindred feel towards each other, and that Sahlins calls "mutuality of being" $(2011$, p.2) and Viveiros de Castro "the mysterious efficacy of relationality" (2009, p.243).

The research on adoption has often addressed the dichotomy nature-culture and its action on the adoptive kinning (e.g. Modell, 1994; Howell, 2006; DiSilvio, 2008; Yngvesson, 2010). From the condition of infertility of the couple - and the feelings associated with it - until the coming of the child into the new family, it is the culture that makes the sense of the private experience of the family's members involved in the adoptive procedures and practices (DiSilvio, 2010b). Thus, the desire for a child - that underlies the 'natural' generative act of the contemporary family - arouses in the lacking parents a sense of incompleteness, which is experienced as a kind of indefiniteness of status, emotionally translatable by the metaphors of the "vacuum to be filled" and the feeling to be "neither meat nor fish" (DiSilvio, 2008, p.166-82). These visions are deeply embedded in the social dispositions through the performative action of a distinctive interpretation of kinship ties, whose plot also implies that the stranger child is assumed as equally incomplete and therefore 'to be filled' because 'missing' a family (like his prospective parents). And if the desire of filiation is established starting from a couple of adults, the willing parents, as the contemporary paradigm of parenthood dictates, then the child's desire can only be mimetic with a specific construction of childhood, according to the Western paradigm of the 'best interests of the child'. So, the wish of the child to be born a 'second time' is established beyond the newborn himself, even when this individual brings with him a personal (alien) originality in the form of biography, memory, relationships. Thus the tension to completeness - that underlies the socially shared representation of the family and imbues the adoptive practices - carries a poietic tension, namely a specific construction of the human (Remotti, 2005), within which it is placed the dual (sequential) movement of emptying the child as 'social person' at the origin and his 'social' filling as adopted son at the arrival (DiSilvio, 2008, p. 57-63; 2012).

\section{The Shifting Polysemous Nature of Adoptive Kinship}

Many scholars highlighted how the adoptive family is conceived as an 'as if' (i.e. Modell, 1994; Yngvesson, 2005, 2010) or as an 'almost the same but not quite' (DiSilvio, 2010a) both in collective representations and private feelings, because of its evident dissimilarity (and perceived uncompleteness). Indeed, although the 'family' may be understood as a social artifact (Bourdieu, 1996), it is clear to all members involved in the private experience as well as in the practices of social workers and institutions that, beyond the rhetorical discourses, the adoptive family is not the biological one. As marked by the adoptees themselves (Modell, 2002; DiSilvio, 2012), growing up in a family is not as being born within it, and having parents 'by law' is not as having 'natural' ones. Everybody has a birth history, a line of ancestors in which one can trace back one's own name and recognize someone by looking at the mirror, while the adoptees have a gap. From this point of view, the 'clean break' that founds the adoptive kinship in the West, enacts the symbolic meaning of exclusivity of the family ties, namely the bond between the parents and the child. In fact, cutting the child's relations at the origin reworks not only the status and the identity of the involved parents, but also reshapes the child's identity into an 'as-ifbegotten' (Modell, 2002, p.5), and the practices of matching performed on children and prospective parents seem to fulfill the need to recompose the gap between 'genealogical connection' and 'parental love', by revealing some anxiety on the possibility to reallocate (in the everyday emotional life) the parental rights over the child.

Many narratives about 'resemblance' are created and spread by the members of the adoptive family, unveiling both the pervasiveness of genomic ideologies and the creative effort of writing the narratives of being relatives lacking a common substance. According to the doxa, to have an adopted son who looks like her/his father/mother so that people say 's/he has your own face', normalizes the relationship and somehow puts it in the same register of biological ties. In fact, the resemblance gives the feeling of a true connection, durable, inherent, something that substantiates a kinship culturally designated as fictive. Several adoptive parents argue that it is easier to build a relationship with a child looking 'familiar', while adoptees assert that, when there are visible similarities with the adoptive parents or other relatives, one intimately feels to belong to that home, and finally 'psy' experts consider the resemblance a great benefit for a good attachment between adoptive mothers and children (Modell, 2002, p.7). Behind these arguments there seems to be a tension to completeness mediated by the cultural belief that blood holds people together and, consequently, that the stronger the mimesis is with the biological family, the more enduring will be the adoptive kinning. However, it is quite ironic to think that adoptive parents and biological ones are complete social strangers and, at the same time, they ideally share such intimate (genetic) traits through the child, even though, as we have already seen, the practice of matching seems to be somehow directed to recompose (rhetorically) this kind of antinomy. It could be argued, following the hegemonic idea of relationship 'between identical', that this (alleged) resemblance talks with the language of belonging, 
bond, enduring solidarity among the adoptive triad itself.

\section{Porous Matters and Creative Subjects}

Although kinship (and family) is still understood as a closed system, made dense by the plot of blood, the lens of kinship 'by law' show the evidence of its porous boundaries. The adoptive kinship seems, indeed, to defy the hegemonic vision of completeness, rhetorically reproduced by genomic, with incompleteness and its benefits. Into the Western thought there is a strong pattern of completeness, where truth is characterized by unity, firmness, immobility. There are no interstices or vacuum, and also multiplicity is conceived as an organization of the constituent parts so as to form a unity (Remotti, 2005, p.34-7; Vattimo, 1961, p.125; Aquinas, 2005, p.243). For a long time, Aristotle's notion of completeness as organization of the parts has exercised its influence not only on the scientific domain, but also in creating a pattern of interpretation of the world and, among others, a specific conception of kinship and the individual. So, the same monadic vision frames the Western concept of 'individual', understood as an indivisible self (or person), unique and original, that is a complete entity. To change, remove or alter a part of this uniqueness would mean altering the self of the person who, in this way, would become a different individual. However, it is through the Cartesian thought, sustained by the disenchanted (in Weberian sense) approach of scientific rationality, that the self-consciousness of the modern man is fully expressed as "buffered-self"(Smith, 2012, p.60). Indeed, in the so-called 'disenchanted (or disengaged) society', people see themselves significantly independent from each other (namely in monadic or atomistic sense), and individuals are conceived as the exclusive makers of their own subjective identities. But albeit the 'disenchanted' scientific approach discloses clear advantages in many knowledge fields, when it is extended beyond the natural sciences and intersects the ontological field of human being, it grossly falsifies the interpretation of the individual's 'being-in-the-world' and does not fully account for the complex daily life of human beings (LiPuma, 1998). It simply represents a particular ideological construct of 'experience-the-world'.

Throughout the twentieth century, the achievement of new epistemological models, and particularly the development of the systems theory, has deployed new knowledge perspectives. So, according to vonBertalanffy (1983), living systems have to be understood as open systems, with porous boundaries, where the content is not structured but repeatedly regenerated through a continuous process of exchange of material/information/energy with the outside world. Its condition, characterized by a permanent precarious balance and therefore by a state of constant relative incompleteness, produces a continuous tension towards balance and completeness that compels to create, invent and seek new formulas (Remotti, 2005, p.40). This means that for open systems what is outside is important as much as what is inside, so that, as Levi-Strauss (1967) highlighted, it becomes intelligible only through the study of its changes, that is the possibility of other different systems to exist.

In the daily life, individuals construct plural identities, often conflicting or competing with each other, intersecting and context-depending (Sökefeld, 1999). Far from being a static core, the self appears as a narrative construction of identity. This dynamic entity finds itself in an unceasing work in progress and manages plural identities through a concerted effort, by providing consistency and continuity to personal experiences. The self is therefore a product of a subjective agency, understood as a creative capability intrinsic to human beings, that provides coherence to the variability of life experiences of the individual. By defying the individualistic-atomistic conception, Taylor (1989) puts the emphasis on the matter that the self's narrative cannot be constructed outside of a dialogical condition that involves one's community/society of belonging. So, the answer to the question "Who are you?" becomes constitutive of the answer to the question "Who am I?", and the understanding of where we are in relation to others, enables us to understand who we are, where we are and how we can get to where we want. The self is after all a story about ourselves that we tell to others and that we use strategically and creatively in different ways and in different cultural contexts (or in the interactions with people that recall different cultural contexts, as we could see in the 'semantic shifting' of "Italian Korean adoptees", "Korean Italian adoptees" and "Koreans" in Kim Soo Bok's speech described above). In a more or less wide perspective, it is also the narrative that people tell us (and themselves) about who we are. The interaction between the individual/singular self and the culture/society is thus reciprocal and mutually constitutive since, as living systems, the persons themselves have porous boundaries that are permeated by what's outside: interpersonal relationships, meanings, rules, practices, beliefs, culturally and historically determined.

\section{Secrets, Biographical Fractures and Right to Information}

The stories of 'search and reunion' widespread by the media, but especially the possibility of those personally involved in 
the adoption to connect with the global world through social networks, seem to lead to a deep change within the 'design' of the child's transfer from an household to another in the West. For some time adoption has become more and more noisy, pushed onto the public arena by the discourses of those social movements that required with a loud voice a reform of the adoptive device, and by many other forces that recently have come into play to counteract the cut between the child's origin and his/her new reallocation (family and national). In regard to this, the case of Korean adoptees may be considered paradigmatic. Since the 90s the associations of Korean adoptees may be considered some of the most highly exposed, very energetic and determined among the adoptive movements that request for a profound changing of the Western ideology of adoption, and the institutional bodies of the country of origin are not irrelevant to the enforcement of this lively social activity. In Italy, as well as in Norway, Sweden, the United States and many other 'receiving' countries, the Consulates of South Korea have played a pivotal role in tracking down the adoptees scattered throughout the countries of coming, in promoting the foundation of associations and facilitating the 'return journeys', economically and logistically. The Korean government, regardless of any political orientation, has been pursuing for years a policy of 'cultural re-appropriation and assimilation' of its 'abandoned' citizens, transferred overseas, providing to the adoptees with the opportunity to study or work in the country of origin, and supporting tenaciously the local agencies that deal with return trips and possibly the search for relatives (Hubinette, 2005; DiSilvio, 2012).

Most of the literature on the origins' issue is based on ethnographic researchs of the contemporary adoptive movements (e.g. Modell, 2002; DiSilvio, 2012) and of the so-called 'return journeys' of adoptees to their origin places (e.g. Yngvesson, 2005). According to Strathern (1999; 2005) and Carsten (2007), the exploration of the role of information on the adoptive kinship and on the adoptees' searching for their birth ties - as well as the knowledge thus gained on their biological relatives - seems to provide a specific comprehension of the way in which this knowledge contributes to the production of both a feeling of connection between relatives and the sense of identity of the individual, and of how the globalization intersects the way in which the family ties are thought of. At the same time, the investigation on pressure groups made up of adoptees, biological and adoptive parents, allows to highlight interesting differences on the symbolic meaning assigned to kinship in the public context and in the private space of family relationships.

The secret at the heart of the family is a recurring theme of many Euro-American popular novels, fairy tales and games. In these frameworks, the return of a relative may have the power to transform, positively or negatively, the lives of those who were (forcibly) separated for a long time. The widespread dissemination of this vision is also consistent with the concept that the knowledge on kinship is constitutive of the identity of the individual, because the information gives shape to what is known about oneself. Strathern (1999) speaks of 'cultural pairing' between (kinship) knowledge and identity, and states that the kinship knowledge is a particular kind of knowledge because the information (and the validation) from which it gleans "is constitutive in its consequences" (p.68). This utterance directly recalls Schneider's (1980) study according to which kinship is conceived by Americans as biogenetic and founded on sexual procreation. So, since the origins imply a kinship and the facts about birth imply a kinning, it is no wonder if the desire expressed by the activists of the adoptive movements to find and meet their biological parents/children is related to both the particular (symbolic) value socially assigned to the origins and the cultural process of making the kinship more and more genetics.

Actually, the search for biological parents and/or relatives is a fairly new phenomenon, and ultimately its dimension is rather finite (Trisielotis, 1973, 1984; Modell, 2002; Howell, 2006). In the early twentieth century, when European States began to institute the reform of child care, many lawmakers were concerned that the confidentiality assigned to important information on the origins, could hinder children in their later search for relevant facts about their identity. So, the government advisers suggested a meticolous surveillance against the alteration of birth information, since "every person has the right to know who he is and where his people are" (Carp, 1998, p.52). Therefore, the original aim was not to deny the access to the information to adoptees - for whom the information was only confidential and not secret - but to protect their biological mothers from the social stigma (Carp, 2002). The process by which the confidentiality turned into secrecy was quite complex, and it seems in some way connected with the spread and increased disciplinary power (in foucaultian sense) of social professions. The State bureaucrats and social workers who had the authority to grant or deny the access to the information were interested in preserving the established rules on adoption, by increasing their influence on the adoptive apparatus, and thus strengthening the success of the professionalization of social work. For over half a century, secrecy became (and remained) pervasive and undisputed, preventing those who had been involved in the adoption from tracing information about the adoptees' origin family and their previous life (Carp, 2002, p.102-3).

The earliest adoptive movements came to life during the years of the claims for civil rights, the affirmation of feminist ideologies, the births' planning and the debate on the status of the family, but only the coming of the neo-liberal ideology of individual rights, made the 'right to know' on one's own origin a pivotal question of both the academic literature and the media debate, a core on which to found the discussion about the future of the adoption in the West 
(DiSilvio, 2012). Nowadays, the established pattern of 'closed' adoption seems to quickly divert toward new attributes of 'openness', and fresh watchwords arise at the horizon of the adoptive kinship like search and access, rights and privileges, autonomy and secrets' revelation, drawing strength from the ambiguous nature of the Western adoptive device (Modell, 2002, p.2; DiSilvio, 2008).

If on the public scene the claim for unveiled origin makes sense within the customary symbolisms of kinship, socially embedded, on the private arena the issue of 'search and reunion' shows complex aspects and not entirely expected (Strathern, 2005). The narratives of adoptees who are searching for their biological parents reveal, indeed, that the desire to acquire information about their origin ties does not simply attain a further expression of the oppositional dichotomies of nature-culture, substance-code, birth-rearing (e.g. Carsten, 2007; DiSilvio, 2012). Actually, rather than led by the predominant (symbolic) idea by which 'blood is thicker than water', adopted people seem inspired by the need to fill a gap in their personal biography that recomposes the temporal continuity of the self by taking back the past they perceive they have been (forcibly) deprived of control. We could talk of a poietic aspiration dictated by the tension to completeness against a biographical perception of incompleteness. However, despite the high value assigned to the physical resemblance, which is expressed in the search for "someone who looks like me" (DiSilvio, 2008, p.206), the narratives and the emotional of adoptees underline not only that the genetic connections continue to exert a strong action in their life but also, surprisingly, that this resemblance is not deemed sufficient to give rise to a kinship tie (Carsten, 2000). In the adoption's domain, indeed, kinship does not 'naturally' exercise a right, but it is a privilege to conquer. The feeling of the lack of an immediate connection is a topic of many narratives of 'reunion', in contrast with media reports that tend to present the event with tones overly romantic or sentimental, by suggesting that lost bonds can simply be reestablished at the point where they were interrupted. But the adoptees provide a different point of view. As in the biological kinship, it is the sedimentation of daily time and care behaviors - understood as efforts and obligations of the relationship - to exert a key role in the production of the kinship's meaning. So, although the 'adoption birth' does not naturally imply the familiar feelings of certainty, durability and solidarity, nevertheless people who undertake the search for origins talk of emptiness in regard to the customary symbolic meanings ruling the kinship's discourse, albeit these descriptions are less discouraged when they involve the biological siblings or half-siblings (Carsten, 2000, p.693). The undermining caused by the adoptive 'break' deprives a person of the historical depth of his own life story, and interrupts the flow of time in relationships, hence the narratives told by those who are searching for their biological parents remind of an intense concern to recover a lost biography, to become complete persons and fill the gap, definitively closing the circle. In seeking to establish new relationships with their birth relatives, adoptees lie in the need to rework kinship symbols, and the way in which they do this suggests that they do not assign high value to the genetic substance as it could be expected. In the 'reunion' frame, indeed, the birth is emptied of the connections to those obligations and rights recognizing the familiar feeling in a traditional sense, not to mention that, from the child's point of view, the adoptive kinship is stripped of the elements of choice or preference that anthropologists generally attribute to the 'fictive' kinship (e.g. Young, 2009).

\section{Invention of Continuity and Co-Production of Memory}

Western kinship founded on sexual procreation seems somehow to be brought into question when time, care and a prolonged effort take place close to the birth in the culture of 'being kin'. The pervasive action of the nature-culture dichotomy within the anthropological hermeneutics has led to significant implications for the understanding (and classification of the different nature of kinship in the West and in the rest of the world. In fact, the adoptive practices have already been the subject of particular attention by the classical studies precisely because they represented an unique scenario to observe the action of distinction (conceived as 'universal') between 'real' kinship relationships, biologically founded, and the bonds of the 'fictive' kinship, not arising from sexual procreation. So, according to several studies on Euro-American kinship (e.g. Schneider, 1980), one would expect to observe an absolutely clear and unambiguous separation between the biological kinship and the 'social' one (Carsten, 2000, p.695). But contemporary studies on new forms of kinship and its social representations show that, in the feelings of family members, what makes the kinship authentic are not the genetic connections but its endurance over time (e.g. Weston, 1991). From this viewpoint, the relationship's cohesion is not only recognized as an inherent attribute of the blood tie, as established by the dominant ideology on kinship, but it may also be actively produced over time.

Young (2009) argues that adoptive relationships are the result of a choice of individuals, made in pairs or individually, but in any case focused on meeting the need for raising one's own children and to being and feeling parents. Her research also points out that the making of a family of choice through adoption represents a relevant illustration of 
changing patterns and signification of the family ties in the post-modern family, which go beyond the 'weight' of the blood. In this case, therefore, the biological processes may be assumed, according to the open system concept, as mere signifiers of the system's changes and flows, rather than as a continuity and control on it. In other words, the people's lived experience suggests that the kinship's symbolic work is much more open and multifaceted than a simple reproduction of hegemonic paradigms, so as the analysis proposed by Schneider seems to assume. The connection, culturally established, between genetics and cohesion of the relationship can therefore be broken up and reconfigured by the temporal dimension that can make 'real' the chosen ties. However, adoptees' narratives seem to return, especially on the emotional level, a loss of the quality of the temporal unit of past-present-future in the way in which it is implicitly woven into the everyday experiences of kinship, providing the milieu to those social events that mark family rituals such as births, marriages, and funerals. In the case of adoption, indeed, these ritual events are detached from their reference context, since the constant and regular accumulation of kinship's exchanges in everyday life has been lost along with the birth's relationship. So, the effort of adoptees seems geared to create new narratives of the self starting from mnemonic objects (birth certificate, photographs, clothes or other signs), sometimes recovered along the 'search'. In some ways, these memory practices recall the tension to put together the kinship ties in the past, even if, by their nature, the biographies produced by mnemonic objects reveal much more the fracture of the kinship ties rather than re-establish connections (Carsten, 2000, p.696). However, these narratives don't show only the presence of the past in the present, they also have to do with the transmission of kinship and of its memory. In fact, just because the adoptees who are searching for their birth ties appear to be well aware that adoptive kinship is founded on fracture and separation, they are particularly concerned to build their own connections between the present and the future.

During my ethnographic field it came to light how one of the reccurring topics of the narratives and motivations of the adoptees' 'search' was the desire to have access to personal health records, especially after a marriage or during a pregnancy. This desire has to do with the fact that if the ties with the past generations have been cut off, the possibility of transmitting (by genetic heritage) something unknown to future generations thickens the family tale by assigning to it a value in the future. Actually the future is not only connected to the present, but cannot also be disconnected from the past, because of the temporal unity assigned to kinship. Therefore, each part of the relation tacitly implies the other parts (Munn, 1992), and the complexity of this fitting effort is highlighted by the difficulty that those adoptees who became parents find in telling their children how they found and met their biological parents.

\section{Constitutive Choices and Textures of the Self}

The discourse of access to information in the adoption domain shows, at the core of the Western kinship practices, a complex intertwining of separations and re-connections between what is apparently inherited from the past and what seemed to be created as new by the adoptive kinning. But presuming a clear trajectory from a world of given connections to another of acquired bonds overshadows some of the most interesting processes that people bring into play when they constitute themselves through their different kinds of relationships. Accessing to the kinship information influences the way in which 'we make kinship' and the sense of the self, and the knowledge produced from this information seems to be constitutive of being and feeling kindred. Within the adoption domain, the strength of this knowledge does not seem to have much to do with the relationships of the past but rather with the discovery of what has been hidden or only partially revealed. So, the 'right to know' seems to gain its constitutive power (of the self) from both the connection between the kinship and the identity and the status of secrecy of the information. Given the positive values assigned by most of the adoptees to their search for biological parents - and despite the relational outcomes are often discouraging - it could be argued that this commitment goes in the direction of satisfying the effort to establish a stronger and coherent identity founded on their true origins and not on lies, as claimed by the protagonists themselves. However, listening to the narratives produced by adoptees, it seems that the value of the information on the origins is inextricably related to the layers of secrecy that these people have met in the course of their life and to their need that such a reality is publicly recognized. The fact that this information is accessible to other people (i.e. social workers, doctors, judges, etc.) but precluded to those who are directly involved in, raises into the adoptees the feeling of having been 'deprived' of their own subjective agency as much as of the knowledge on it. Thus, the search for and the reunion with their biological parents becomes a way to reassert the control over their own lives, through the appropriation of a deeply intimate (and constitutive) past (Carsten, 2007, p.416).

According to Strathern (1999), in the Euro-American kinship's culture, to gain a certain degree of knowledge about one's own ancestry/progeny implies to acquire an identity. This occurs since it is a kind of knowledge that produces an immediate effect on individuals due to the action played by the embedded dispositions about being relatives. Once 
gained, the kinship knowledge cannot be rejected or put aside since, as Strathern asserts, "the relationship enters into life when the knowledge is given" (p.78), that is, it constitutes relationships whether the relationship is recognized or not. Hence, within the kinship's reality, the new information prevents any choice because, by using Strathern's words (1999, p.75) "to choose between two facts is also a choice between two relationships", and this choice is constitutive of the identity in the relational context. This condition seems to be confirmed by the distress of the adoptive parents to disclose to their children what they know on their biological relatives, in particular on siblings left behind. And it is also strengthened by the experience reported by adoptees according to which the new information seems to quickly impose a trajectory to their actions until, possibly, dominating the lives of those directly or indirectly involved into the experience. Many adoptees remark that, although they had been advised to proceed carefully in the search for a 'reunion' with their biological parents, once they found an address or a phone number, they felt the urge to immediately get in contact with them (Carsten, 2007). However, if the knowledge of one's family relationships exerts a 'constitutive' action of the self, then even the decision of not searching for biological parents or relatives can be seen as constituting one's own identity. So, many adoptees assert that they have not started a search because of the anxiety of causing a double-bind situation both in themselves and in the closest persons. These voices suggest that the constitutive effects of the origins' information have the potential to affect others, beyond the adoptees themselves and their biological parents. So, the mighty concern for the ties with the adoptive parents is understandable, when these relationships are the majority of the living experience of the kinship in the present as well as in the past, lived by adopted people.

Many adoptees assert they haven't given way immediately to the information they had found, but they left it aside and neglected it for several years, until different stages of their lives provided them the motivation to resume that information. The marriage, the birth of a child or the death of one of the adoptive parents have often represented the restart point of the search. Actually, as several studies highlight (e.g. Trisielotis, 1984; Carsten, 2007), it seems that the search for biological parents follows a particular chronological order which depends on the personal life story. This brings out the story of Beatriz, a twenty-five years old girl adopted from Brazil at the age of a few months, who I have been meeting with for a couple of years during my ethnographic field. When she was a teen, Beatriz was back to her places of origin together with her adoptive parents and some friends, but this trip did not raise in her any interest or desire to know. Now that she will be married next month - she confided to me - she felt for the first time a vague desire to know something more about her biological relatives and her family history. The ethnographic data collected on the field show the actualization of a wide variety of strategies in relation to the birth's information - from going to the end to not trying at all, or giving oneself some limits at different points of the search. Adoptees can limit the information about their origin, stop and resume the search, act immediately or postpone further steps for a long time, and further moves are often related to current family circumstances and suggest a rather complex interweaving among the kinship chronologies of the past, present and future. Somehow, this seems to indicate that the 'constitutive power' of the kinship knowledge can be negotiated in ways that do not necessarily restrict the choices in one binding direction (Carsten, 2007, p.420).

Actually, if the relationship is established even outside of the small daily acts and rituals, the possibility of a coproduction of a shared memory can be considered a real creative aspiration. According to the definition provided by Holtzman (2006), the memory can be understood as the subjective manner in which the past is recalled, evoked and used to build the present, involving a large collection of disparate processes (p.363). And since memory and identity are closely related, the narrative of the past can be used to repair the fractures of time and build a continuum of identity (Atze, Lambek, 1996). In fact, as discussed above, the answer to the question "Who am I?" is strictly connected to what one remembers and to the narratives told by others on the past. Consequently, not only the memory is socially constituted in the narratives, but also the very enactment of the self is produced through remembering. In the narratives of "search and reunions" told by the adoptees, often associated with memory objects, one can see the effort to create the sense of a continuous self, but also to regain control over his own past. Sharing this (reworked) memory of the past with others, as well as the telling act, provides (social) thickness to the creative control on the events of one's own life. This statement of subjective agency can somehow explain the gap between the positive value assigned to the search and the discouraging relational outcome of the 'reunion' with biological parents or relatives. In fact, despite these reunions do not create deep relational connections, they allow adoptees to activate the feeling of having chosen firsthand their ties of kinship. The intense memory activity (and the dialogue between two different narratives of kinship) actually produces the idea of sliding scenarios of family tales that, although they underline the sense of incompleteness intrinsic to the adoptive experience, they do not concern the memory, but rather the relationship (of birth or adoption) to which the adoptees have been subject. 


\section{Conclusions}

Over the last decades, the debate on adoptive kinship in the West is renewing the dialectic on the kinship's meaning, on being relatives and its social recognition, and under the cover of old symbolisms new ideologies of kinship, family, parenting and identity slowly take shape. In particular, the issue of secrecy on the birth information and the claim of the 'right to know' by the biological 'junctions' of the adoptive triad show the close connection between the kinship's declination in the contemporary world, the neo-liberal ideologies and the global information. In fact, the claim to access the information on family ties acquires one's own specific value into the historical and cultural framework shaped by the increase in global connections provided by the new technologies, the neo-liberal claim to the 'right' of individuals and the socio-biological drift dictated by the actions of the genetics on the collective representation of kinship. However, the initiatives of 'search and reunion' do not achieve their goal by simply accessing or refusing information. Indeed, although the kinship knowledge represents a constitutive tool of the self, people not only choose the level of knowledge to be accessed, but also implement different trajectories regarding the use of the knowledge itself. There are many possibilities, creative or destructive, offered by the knowledge in the emotionally complex and dense space of the family, and this suggests that there are many ways in which the kinship knowledge is constitutive of the self. Most of those involved in the searching for their ties of origin are often aware of the destabilizing effects that the new information on kinship can cause on themselves as well as on close people. On the other hand, the way in which adoptees rework memory, showing the past in the light of the present (so as both adoptive and biological parents do when they have to face the making of a new family and when have to place the event of abandonment within their life tale rispectively), accounts for the relevance of the sense of continuity of past-present-future in the establishment of the self and in the poietic tension to the biographic completeness. And albeit these 'reunions' will never completely restore the flow of time as it is commonly experienced within the kinship, nevertheless by highlighting how the biology itself is not sufficient to create a connection, they make clear the fiction at the core of the biogenetic paradigm of family relationships.

\section{References}

Acquino, T. (2005). Commento alla metafisica di Aristotele. Vol. 2 (5-8). Bologna: ESD.

Agamben, G. (2005). Homo Sacer. II potere sovrano e la nuda vita. Torino: Einaudi.

Aristotele (2000). Etica Nicomachea. Milano: Bompiani.

Atze, P. \& Lambek, M. (Ed.) (1996). Tense Past: Cultural Essay in Trauma and Memory. London: Routledge.

Bourdieu, P. (1996). On the Family as a Realized Category. Theory, Culture \& Society, 13(3), 19-26.

Carp, E.W. (1998). Family Matters: Secrecy and Disclosure in the History of Adoption. Cambridge: Harvard University Press.

Carp, E.W. (2002). Adoption, Blood Kinship, Stigma, and the Adoption Reform Movement: A Historical Perspective. Law \& Society, 3(2), 433-460.

Carsten, J. (2000). 'Knowing You've Come From': Ruptures and Continuities of Time and Kinship in Narratives of Adoption Reunions. Journal of the Royal Anthropological Institute, 6(4), 687-703.

Carsten, J. (2007). Constitutive Knowledge: Tracing Trajectories of Information in New Contexts of Relatedness. Anthropological Quarterly, 80(2), 403-426.

DiSilvio, R. (2008). Parentele di confine. La pratica adottiva tra desiderio locale e mondo globale. Verona: Ombre Corte.

DiSilvio, R. (2010a). 'Almost the same but not quite': Fight Between Nature and Culture in Italian Adoptive Rules and Devices. Conference Paper. Paris: FSMH. Retrievable on WebSite: http://unimib.academia.edu/RossanaDiSilvio/Papers/

DiSilvio, R. (2010b). The 'Truth that Can Be Told': Re-writing Broken Identities to Inventing a 'True' Family Tale in Transnational Adoption. Conference Paper. Leiden: ICAR3. Retrievable on WebSite: http://unimib.academia.edu/RossanaDiSilvio/Papers/

DiSilvio, R. (2012). Genitori del 'come se'. Le associazioni di famiglie adottive tra marginalità, legittimazione e appartenenza. In Koensler, A. \& Rossi, A. (Eds.), Comprendere il dissenso. Etnografia e antropologia dei movimenti sociali. 121-132. Perugia: Morlacchi.

Holtzman, J. (2006). Food and Memory. Annual Review of Anthropology, 35, 361-378.

Howell, S. (2006). The Kinning of Foreigners: Transnational Adoption in a Global Perspective. New York: Berghahn Books.

Levi-Strauss, C. (1967). Razza, storia e altri studi di antropologia. Torino: Einaudi.

LiPuma, E. (1998). Modernity and Forms of Personhood in Melanesia. In Lambeck, M. \& Strathern, A. (Eds.), Bodies and Persons: Comparative Perspectives from Africa and Melanesia. 53-79. Cambridge: Cambridge University Press.

Kahn, C. H. (1997). Philosophy Before Socrates. Ancient Philosophy, 17(1), 159-163.

Malinowski, B. (1930). Kinship. Man, 30(2), 19-29.

Modell, J. (1994). Kinship With Strangers: Adoption and Interpretation of Kinship in American Culture. Berkeley: University of California Press.

Modell, J. (2002). A Sealed and Secret Kinship: The Culture of Policies and Practices in American Adoption. New York: Berghahn Books. 
Munn, N. (1992). The Cultural Anthropology of Time: A Critical Essay. Annual Review of Anthropology, 21, 93-123.

Remotti, F. (2005). Sull'incompletezza. In Affergan, F. et al.(Eds.), Figure dell'umano. 21-89. Roma: Meltemi.

Sahlins, M. (2010). Un grosso sbaglio. L'idea occidentale di natura umana. Milano: Eléuthera.

Sahlins, M. (2011). What Kinship Is?(Part One). Journal of the Royal Anthropological Institute, 17(1), 2-19.

Schneider, D. (1980). American Kinship: A Cultural Account. Chicago: University of Chicago Press.

Smith, K. (2012). From Dividual and Individual Selves to Porous Subjects. Australian Journal of Anthropology, 23(1), 50-64.

Sokefeld, M. (1999). Debating Self, Identity and Culture in Anthropology. Current Anthropology, 40(4), 417-448.

Strathern, M. (1999). Refusing Information. In Strathern, M. (Eds.), Property, Substance and Effect: Anthropological Essays on Persons and Things. London: Athlone Press.

Strathern, M. (2005). Kinship, Law and the Unexpected: Relatives Are Always a Surprice. New York: Cambridge University Press.

Taylor, C. (1989). Sources of the Self: The Making of the Modern Identity. Cambridge: Cambridge University Press.

Triseliotis, J. (1973). In Search of Origins: The Experiences of Adopted People. London: Routledge \& Kegan.

Triseliotis, J. (1984). Obtaining Birth Certificates. In Philip, B. (Eds.), Adoption: Essays in Social Policy, Law and Sociology. 38-53. New York: Tavistock Publishers.

Vattimo, G. (1961). II concetto di fare in Aristotele. Torino: Giappichelli.

Viveiros de Castro, E. (2009). The Gift and the Given: Three Nano-Essays on Kinship and Magic. In Bamford, S. \& Leach, J. (Eds.), Kinship and Beyond: The Genealogical Model Reconsidered. 237-268. NewYork: Berghahn Books.

Von Bertalanffy, L. (1983). Teoria generale dei sistemi. Milano: Mondadori

Yngvesson, B. (2005). Going 'Home': Adoption, Loss of Bearings and the Mythology of Roots. In Volkman, T. A. (Eds.), Cultures of Transnational Adoption. 25-48. Durham: Duke University Press.

Yngvesson, B. (2010). Belonging in an Adopted World: Race, Identity and Transnational Adoption. Chicago: University of Chicago Press.

Young, A. (2009). Families of Choice: A Qualitative Study of Australian Families Formed Through Intercountry Adoption. PhD Thesis: University of Sidney. Unpublished

Weston, K. (1991). Families We Choose: Lesbians, Gays, Kinship. New York: Columbia University Press. 